\title{
Crisis management during anaesthesia: sepsis
}

\section{J A Myburgh, M J Chapman, S M Szekely, G A Osborne*}

Qual Saf Health Care 2005;14:e22 (http://www.qshc.com/cgi/content/full/14/3/e22). doi: 10.1136/qshc.2002.004234

*Dr Osborne died before this research was published.

See end of article for authors' affiliations .....................

Correspondence to: Professor W B Runciman, President, Australian Patient Safety Foundation GPO Box 400, Adelaide, South Australia, 5001 Australia; research@apsf. net.au

Accepted 12 January 2005
Background: Anaesthesia with concurrent sepsis is risky, and involves consideration of possible organ dysfunctions-respiratory, cardiovascular, renal, and haematological-as well as ensuring that appropriate antibiotics are given after taking the necessary microbiological specimens. Because prompt attention needs to be paid to so many body systems, the place for a structured approach during anaesthesia for a septic patient was assessed.

Objectives: To examine the role of a previously described core algorithm "COVER ABCD-A SWIFT $\mathrm{CHECK}^{\prime}$, supplemented by a specific sub-algorithm for sepsis, in the management of sepsis occurring in association with anaesthesia.

Methods: The potential performance of this structured approach for each of the relevant incidents among the first 4000 reported to the Australian Incident Monitoring Study (AIMS) was compared with the actual management as reported by the anaesthetists involved.

Results: Sepsis was identified as the primary problem in 13 of the first 4000 reports ( $<1 \%)$ to AIMS. The incidents reported generally occurred in sick patients; $70 \%$ were ASA status III or worse. The COVER $A B C D$ algorithm provided a diagnosis and corrective manoeuvre in only $15 \%(2 / 13)$ of reported incidents, and the sepsis sub-algorithm provided adequate therapeutic strategies in a further $38 \%(5 / 13)$ of the incidents. Eight cases required the use of additional sub-algorithms for desaturation (30\%), cardiac arrest (15\%), hypotension (8\%), and aspiration (8\%).

Conclusion: Sepsis involves a serious physiological stress upon multiple organ systems. The use of a structured approach involving a core algorithm and additional sub-algorithms as required provides a series of checklists that can successfully deal with the complex multiple and interrelating problems that these patients present.
$\mathrm{S}$ epsis has been defined as the systemic response to infection. ${ }^{1}$ Prompt and effective resuscitation, rational prescription of antibiotics and where appropriate, surgical debridement and drainage are the essentials in the treatment of severe infections. Anaesthesia with concurrent sepsis is risky, and involves consideration of possible organ dysfunctions including respiratory, cardiovascular, renal, and haematological-as well as ensuring that appropriate antibiotics are given after taking the necessary microbiological specimens.

Patients with sepsis usually demonstrate signs of the systemic inflammatory response syndrome (SIRS), a nonspecific clinical syndrome resulting from a generalised response to inflammation. ${ }^{2}$ This may be caused by a variety of infectious and non-infectious causes (for example, pancreatitis, burns, multiple trauma). It generally manifests as an increased cardiorespiratory and immunological response to meet increased metabolic requirements imposed by the insult. Because prompt attention needs to be paid to so many body systems to encompass the needs of a septic patient during an anaesthetic, the place for a structured approach was assessed.

In 1993, a "core" crisis management algorithm, represented by the mnemonic COVER ABCD-A SWIFT CHECK (the $\mathrm{AB}$ precedes COVER for the non-intubated patient), was proposed as the basis of a systemic approach to any crisis during anaesthesia where it is not immediately obvious what should be done, or where actions taken have failed to remedy the situation. ${ }^{3}$ This was validated against the first 2000 incidents reported to the Australian Incident Monitoring Study (AIMS). AIMS is an ongoing study which involves the voluntary, anonymous reporting of any unintended incident which reduced, or could have reduced the safety margin for a patient. ${ }^{4}$
It was concluded that if this algorithm had been correctly applied, a functional diagnosis would have been reached within 40-60 seconds in 99\% of applicable incidents, and the learned sequence of actions recommended by the COVER portion would have led to appropriate steps being taken to handle the $60 \%$ of problems relevant to this portion of the algorithm. ${ }^{3}$ However, this study also showed that the $40 \%$ of problems represented by the remainder of the algorithm, ABCD-A SWIFT CHECK, were not always promptly diagnosed or appropriately managed..$^{3-5}$ It was decided that it would be useful to develop a set of sub-algorithms in an easy to use crisis management manual ${ }^{6}$ for these remaining problems. This study reports on the potential place of the COVER ABCD-A SWIFT CHECK algorithm in the diagnosis and initial management of sepsis, provides an outline of a specific crisis management algorithm for sepsis during anaesthesia, and gives an indication of the potential value of using this structured approach.

\section{METHODS}

Of the first 4000 incidents reported to AIMS, those that made reference to sepsis were extracted and analysed for relevance, presenting features, type of surgery, cause, management, and outcome. The COVER ABCD-A SWIFT CHECK algorithm, as presented elsewhere in this set of articles, ${ }^{6}$ was applied to each relevant report to determine the stages at which the problem might have been diagnosed and to confirm that activating the COVER portion would have led to appropriate initial steps being taken.

As sepsis was not adequately dealt with by this algorithm, a specific sub-algorithm was developed for these problems (see fig 1), and its putative effectiveness was tested against the reports. How this was done is described elsewhere in this set of articles. ${ }^{6}$ The potential value of this structured approach 
(that is, the application of COVER ABCD-A SWIFT CHECK to the diagnosis and initial management of this problem, followed by the application of the sub-algorithm for sepsis) was assessed in the light of the AIMS reports by comparing its potential effectiveness for each incident with that of the actual management, as recorded in each report.

\section{RESULTS}

There were 36 reports that contained the word "sepsis". Of these, 13 were associated with specific sepsis related events and were analysed for this study. The remaining 23 reports related to other incidents in which sepsis did not play a significant role. Physical (ASA) status is shown in table 1 .

Presenting features are shown in table 2, and features of the procedure and patient in table 3 .

In summary, the incidents reported generally occurred in very sick patients; $69 \%$ were ASA status III or worse (table 1 ). Diabetic, immunocompromised, and intensive care patients undergoing procedures for urological, biliary, or cutaneous infections were represented. Cardiorespiratory compromise presenting as desaturation (77\%), hypovolaemia (46\%), and hypotension $(30 \%)$ were the most common presentations (table 2). These incidents occurred most frequently at intubation (37\%), following extubation, or in the immediate postoperative period $(67 \%)$. Premature extubation requiring
Table 1 Classification according the American Society of Anesthesiologists (ASA)

\begin{tabular}{lllr}
\hline ASA status* & Definition & n (= 13) & $\%$ \\
\hline I & Healthy patient & 1 & 8 \\
II & Mild systemic disease & 3 & 23 \\
III & Moderate systemic disease & 6 & 46 \\
IV & Severe systemic disease & 2 & 15 \\
V & Moribund patient & 1 & 8 \\
\hline \multirow{2}{*}{$38 \%(5 / 13)$ patients were emergencies. } & & \\
\end{tabular}

reintubation for respiratory failure was common (62\%) and of these patients, the majority $(75 \%)$ required postoperative ventilation in the intensive care unit. Volume resuscitation was used in $46 \%$, and inotropic support in $40 \%$.

The COVER ABCD algorithm and the sepsis sub-algorithm were sufficient for adequate management in just over half of the patients; however, eight cases required additional subalgorithms for desaturation $(30 \%),{ }^{7}$ cardiac arrest $(15 \%),{ }^{8}$ hypotension $(18 \%),{ }^{9}$ and aspiration $(8 \%){ }^{10}$

\section{DISCUSSION}

This study analysed incidents from 4000 AIMS reports where sepsis or infection related incidents were identified during

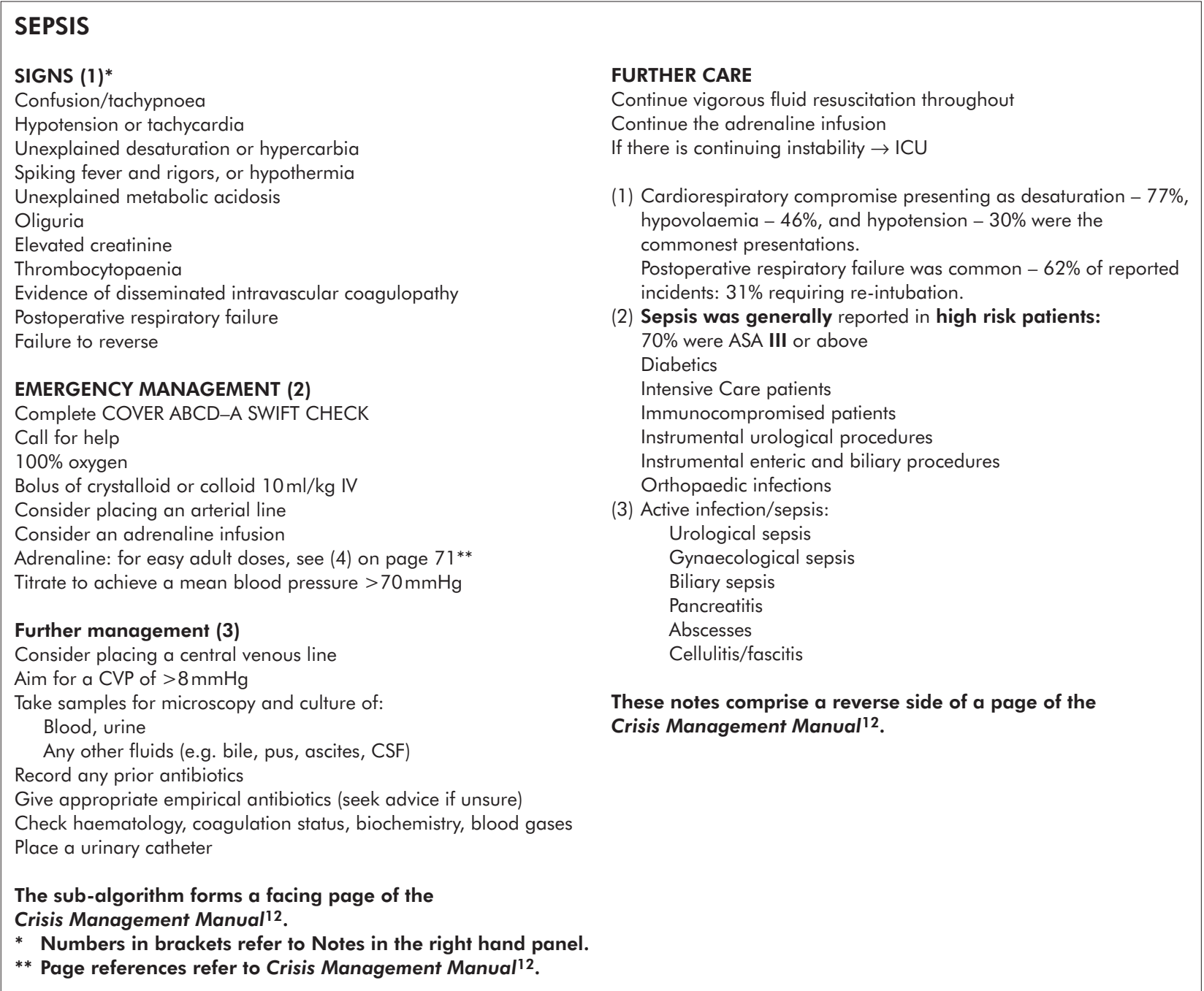

Figure 1 Sepsis. 
Table 2 Classification of reports according to presenting incident $^{*}$

\begin{tabular}{lll}
\hline Presenting feature* $^{*}$ & n (= 13) & $\%$ \\
\hline Desaturation† & 10 & 77 \\
Postoperative respiratory failure & 8 & 62 \\
Hypovolaemia & 6 & 46 \\
Hypotension & 4 & 31 \\
Reintubation§ & 4 & 31 \\
Hypercapnia & 3 & 23 \\
Fever, rigours & 3 & 23 \\
\hline
\end{tabular}

*There was more than one presenting feature in many of the reports. †Desaturation occurred at induction, intraoperatively and postextubation in three, two, and five cases respectively.

\#Six patients required transfer to ICU, two patients recovered.

$\S$ Three recovered and one patient required transfer to ICU.

anaesthesia. Sepsis is the systemic response to infection and represents a continuum of illness severity from minor constitutional signs (fever, tachycardia, leucocytosis) to septic shock and multiple organ failure. The duration of this response is variable and may persist into the postoperative period. Initially, it represents an endogenous mediator driven response to increase the patient's capacity to meet the metabolic demands imposed by the septic insult. This may manifest as an increase in cardiorespiratory drive in order to increase oxygen delivery. In the normal individual, this endogenous response is well tolerated. Associated cardiorespiratory comorbidities and reduced immunocompetence by diseases such as diabetes, malignancy, or by drugs may reduce the capacity of the patient to meet these increased metabolic demands. Certain infections such as gram negative or gram positive septicaemia may induce an overwhelming septic insult that exhausts the reserve of the patient. ${ }^{1-3}$

Assiduous attention to resuscitation with defence of appropriate blood pressure and cardiac output in patients with potential or overt sepsis is paramount. This applies equally to the preoperative period, throughout the procedure, and into the postoperative period. Advances in monitoring such as pulse oximetry and measurement of intravascular pressures have become routine and facilitate the assessment of oxygenation and perfusion in these patients. ${ }^{11}$

The limited data from this study confirm that septic patients undergoing anaesthesia for procedures directed at the underlying septic problem are vulnerable to hypoxia and hypotension during the perioperative period. It is vital to eliminate any causes of desaturation or hypotension that are unrelated to the underlying septic problem. These are diagnosed and corrected by the COVER ABCD algorithm, and, if necessary, the desaturation, hypotension, and any other relevant sub-algorithms. When the cause of desaturation or hypotension remains obscure, sepsis or SIRS should be considered to be the mechanism. A "sepsis" sub-algorithm for anaesthesia (fig 1) is proposed in these circumstances. Unexpected desaturation during intubation and hypotension following induction of anaesthesia are manifestations of increased metabolic demands and hypovolaemia that are hallmarks of sepsis. The majority of reports pertained to incidents that occurred in the immediate postoperative period, where premature extubation and postoperative cardiorespiratory failure might have exposed the limited reserve of the patient. These patients should be transferred to an intensive care unit for postoperative ventilation and management.

In the control of sepsis, the use of a structured approach involving a core algorithm and any necessary sub-algorithm provides a series of checklists in what otherwise can become an overwhelmingly complex set of problems. This also ensures that an additional, unrelated problem is not compromising the patient.
Table 3 Classification of reports according to procedure performed and patient features

\begin{tabular}{llr}
\hline Classification of reports & $\mathbf{n}(=13)$ & $\%$ \\
\hline Procedure & 4 & 31 \\
$\quad$ Urological & 4 & 31 \\
Enteric & 1 & 8 \\
Biliary & 1 & 8 \\
$\quad$ Cutaneous/orthopaedic infections & 5 & 38 \\
Patients & 2 & 15 \\
$\quad$ Diabetic patients & 1 & 8 \\
Intensive care patients & & \\
Immunosuppressed patients & & \\
\hline
\end{tabular}

\section{Key messages}

- Sepsis was identified as the primary problem in 13 of the first 4000 incidents reported to AIMS.

- Seventy per cent of the patients were graded ASA III or worse; one patient was moribund.

- The commonest performed procedures were urological, enteric, biliary, and cutaneous/orthopaedic.

- Thirty eight per cent of the patients were diabetic. Eight per cent were immunosuppressed.

- Commonest presenting incidents in the series were: desaturation (77\%); postoperative respiratory failure (62\%); hypovolaemia (46\%); hypotension (31\%).

- Seventy five per cent required postoperative ventilation in the ICU. Volume replacement was used in $46 \%$ and inotropes in $40 \%$.

- The COVER ABCD core algorithm and the sepsis subalgorithm were adequate for the management of just over half the patients. However additional sub-algorithms were required for eight cases, namely desaturation $(30 \%)$, hypotension (18\%), cardiac arrest $(15 \%)$, and aspiration (8\%).

\section{ACKNOWLEDGEMENTS}

The authors would like to thank all the anaesthetists in Australia and New Zealand who contributed to the 4000 incident reports upon which this and the other 24 papers in the Crisis Management Series are based. The coordinators of the project also thank Liz Brown for preparing the draft of the original Crisis Management Manual; Loretta Smyth for typing; Monika Bullock, RN, for earlier coding and classifying of data; Dr Charles Bradfield for the electronic version of the algorithms; Dr Klee Benveniste for literature research; Drs Klee Benveniste, Michal Kluger, John Williamson, and Andrew Paix for editing and checking manuscripts.

\section{Authors' affiliations}

J A Myburgh, Associate Professor, University of New South Wales, Director of Research, Department of Intensive Care Medicine, The St. George Hospital, Sydney, Australia

M J Chapman, Senior Staff Specialist, Intensive Care Unit, Royal Adelaide Hospital and University of Adelaide, Adelaide, South Australia, Australia

S M Szekely, Senior Staff Specialist, Department of Anaesthesia and Intensive Care, Royal Adelaide Hospital and University of Adelaide, Adelaide, South Australia, Australia

G A Osborne, Senior Staff Specialist, Department of Anaesthesia and Intensive Care, Royal Adelaide Hospital and University of Adelaide, Adelaide, South Australia, Australia

The study was coordinated by the Australian Patient Safety Foundation, GPO Box 400, Adelaide, South Australia, 5001, Australia. 


\section{REFERENCES}

1 Matot I, Sprung CL. Definitions of sepsis. Intensive Care Med 2001;27/Suppl 1):S3-9.

2 Muckart DJ, Bhagwanjee S. American College of Chest Physicians/Society of Critical Care Medicine Consensus Conference definitions of the systemic inflammatory response syndrome and allied disorders in relation to critically injured patients. Crit Care Med 1997; 25:1789-95.

3 Runciman WB, Webb RK, Klepper ID, et al. Crisis management: validation of an algorithm by analysis of 2000 incident reports. Anaesth Intensive Care 1993:21:579-92.

4 Webb RK, Currie M, Morgan C, et al. The Australian Incident Monitoring Study: an analysis of 2000 incident reports. Anaesth Intensive Care 1993;21:520-8.

5 Webb RK, van der Walt JH, Runciman WB, et al. Which monitor? An analysis of 2000 incident reports. Anaesth Intensive Care 1993;21:529-42.

6 Runciman WB, Kluger MT, Morris RW, et al. Crisis management during anaesthesia: the development of an anaesthetic crisis management manual. Qual Saf Health Care 2005; 14:e1.
7 Szekely SM, Runciman WB, Webb RK, et al. Crisis management during anaesthesia: desaturation. Qual Saf Health Care 2005; 14:e6.

8 Runciman WB, Morris RW, Watterson LM, et al. Crisis management during anaesthesia: cardiac arrest. Qual Saf Health Care 2005; 14:e14.

9 Morris RW, Watterson LM, Westhorpe RN, et al. Crisis management during anaesthesia: hypotension. Qual Saf Health Care 2005; 14:e1 1 .

10 Kluger MT, Visvanathan T, Myburgh JA, et al. Crisis management during anaesthesia: regurgitation, vomiting, and aspiration. Qual Saf Health Care 2005; 14:e4.

11 Runciman WB, Webb RK, Barker L, et al. The pulse oximeter: applications and limitations - an analysis of 2000 incident reports. Anaesth Intensive Care 1993;21:543-50.

12 Australian Patient Safety Foundation. Crisis Management Manual: COVER $A B C D$ A SWIFT CHECK. Adelaide: Australian Patient Safety Foundation, 1996, 74 pp. Available at http://www.apsf.net.av/anaesthesia.htm (accessed 6 September 2004). 